\title{
Anaphylactic shock with methylprednisolone, Kounis syndrome and hypersensitivity to corticosteroids: a clinical paradox
}

\author{
Nicholas G. Kounis ${ }^{1 *}$ D, loanna Koniari ${ }^{2}$, George D. Soufras ${ }^{3}$ and Emmanouil Chourdakis ${ }^{4}$
}

\begin{abstract}
Corticosteroids are widely used for the treatment of allergic reactions but paradoxically themselves may induce acute, delayed, local or systemic allergic reactions and even anaphylaxis with Kounis syndrome. They can suppress the release of arachidonic acid from mast cell membranes, via phospholipase A2 and eicosanoid biosynthesis inhibition. Corticosteroids can promote cell apoptosis and mediate in annexin or lipocortin synthesis, substances that modulate inflammatory cell activation, adhesion molecule expression, transmigratory and phagocytic functions. Antigen-antibody reaction, hapten formation, and medication contaminants are some of the incriminated causes. Patients with atopic diathesis are particularly vulnerable. Complete and thorough previous history of drug reactions or allergies is necessary before administration of any particular medication including corticosteroids.
\end{abstract}

\section{To the editor}

In the interesting report published in Italian Journal of Pediatrics [1], an one-year-old male patient suffering from polymalformative syndrome with previous gastrostomy for necrotizing enterocolits and anaphylaxis to cow's milk proteins, developed repeated episodes of anaphylaxis with urticaria, eyelid edema, tightened laryngospasm and severe dyspnea which occurred within few minutes following intravenous administration of $10 \mathrm{mg}$ of methylprednisolone sodium succinate. Skin prick tests and intradermal tests with pure methyl-prednisolone sodium succinate were positive for formulation of $40 \mathrm{mg}$ and negative for formulation of $125 \mathrm{mg}$. SDS-PAGE (sodium dodecyl sulfate-polyacrylamide gel electrophoresis) and Immunoblotting methods confirmed the presence of allergenic milk proteins in ten different batches of the implicated product (Solu-Medrol $40 \mathrm{mg}$, Pfizer).

This report raises the following issues on corticosteroid actions and interactions, the immunogenic role of

\footnotetext{
* Correspondence: ngkounis@otenet.gr

'Department of Cardiology University of Patras Medical School, Rion, 7

Aratou Street, Queen Olgas Square, 26221 Patras, Achaia, Greece

Full list of author information is available at the end of the article
}

corticosteroid esters and the atopic diathesis-associated immune disorders:

1. Corticosteroids are potent anti-inflammatory and immunomodulating agents which can:

a. Suppress the release of arachidonic acid from mast cell membranes, via inhibition of phospholipase A2, and inhibit eicosanoid biosynthesis [2]

b. Promote cell apoptosis, via autocrine or paracrine pathway involving the up-regulation of the death receptor CD95 and its ligand CD95L [3]

c. Induce annexin or lipocortin synthesis, which modulate inflammatory cell activation, adhesion molecule expression, transmigratory and phagocytic functions [4].

2. Systemic corticosteroids can induce allergic reactions via the following mechanisms:

a. Classical antigen-antibody reactions to corticosteroids and contaminants. Indeed, IgE antibodies to methylprednisolone have been demonstrated in anaphylactic reaction after infusion of methylprednisolone [5]. 
b. Hapten formation via steroid glyoxal, that is a cortisol degradation product whose aqueous solution could be also responsible for the steroid carbon rings to the body immune system [6].

c. Since the immunogenic role of succinate esters have greater solubility in water and higher affinity to serum proteins, the hapten formation is facilitated and acts as complete antigen [7]

3. Succinate esters of hydrocortisone and methylprednisolone are the drugs that are most frequently responsible for type 1 (immediate) allergic reactions. Indeed, different affinities of hydrocortisone acetate, hydrocortisone sodium phosphate, and hydrocortisone sodium succinate to serum and cutaneous proteins have been demonstrated [8]. However, intravenous administration of $200 \mathrm{mg}$ of hydrocortisone sodium phosphate, for treatment of status asthmaticus [9], has induced itching, macular rash, paresthesiae, tremor of the arms and legs, and nausea and vomiting in 16 patients suffering from chronic asthma.

4. The described patient had experienced anaphylaxis due to cow's milk proteins administered through gastrostomy when he was 4 months old. Therefore he could be suffered an atopic diathesis. Atopic diathesis involves genetics, immune system dysfunction, environmental exposures, and difficulties with the permeability of the skin. It results from complex abnormalities of the innate and adaptive immune systems. This condition refers to an inherited tendency to produce IgE antibodies in response to small amounts of common environmental factors and atopic patients are easily developed an allergic reaction when they are exposed to such factors. Recent reports have shown that atopic patients suffering from systemic lupus erythematosus have more severe disease at diagnosis and poorer outcomes than SLE patients without atopy [10]. Furthermore, late-onset anaphylactic reactions following intravenous cyclophosphamide pulse in a patient with systemic sclerosis and systemic lupus erythematosus overlap syndrome have been also encountered [11]. Therefore, atopy seems to constitute a disease-substrate that predispose to allergic and anaphylactic reactions. Indeed, a 32-year-old woman suffering from atopic dermatitis [12], without any previous history of food or drug allergy, no suggestive family history, and no other systemic diseases, developed erythematous patches with slight elevation and itching on the face, trunk, and both hands after $0.7 \mathrm{~mL}$ of intralesional triamcinolone solution with concentration $2.5 \mathrm{mg} / \mathrm{mL}$ on her dorsum of both hands. Her symptoms worsened with therapeutic intravenous re-administration of dexamethasone and she recovered only after treatment with epinephrine

5. In another recent report, a 52-year-old female patient, without previous history of any illness, developed severe retrosternal pain with electrocardiographic ST depression at II, III, aVF, and V3-V6 leads $15 \mathrm{~min}$ following $40 \mathrm{mg} / \mathrm{ml}$ of intramuscular triamcinolone acetonide (Kenacort-A Retard IM ampule) administration for rashes and itching of her scalp. Troponin was raised (TnI: $0.98 \mathrm{ng} / \mathrm{mL}$ ), but, on coronary angiography, her coronary arteries were found normal and she recovered with antihistaminic therapy with a final diagnosis of variant type I Kounis syndrome [13]. Additionally, two patients developed anaphylactic shock, with cutaneous and systemic manifestations, following methylprednisolone succinate pulse therapy for neuromyelitis optica and systemic lupus erythematosus [14]. Intradermal skin tests with various types of corticosteroids revealed positive reaction to succinate-containing methyprednisolone, prednisolone, and hydrocortisone in both patients.

6. Furthermore, another 52-year-old woman with a previous history of allergy to anti-haemorrhoid creams and ointments, developed generalized symmetrical pruritic eruption following intra-articular administration of $1 \mathrm{ml}$ of triamcinolone acetonide. Patch tests were positive to tixocortol pivalate, budesonide, hydrocortisone butyrate, nickel sulfate and potassium dichromate. Intradermal skin prick test was positive to triamcinolone and oral challenge tests were positive to deflazacort and methylprednisolone after 14 and $24 \mathrm{~h}$ respectively accompanied by pruritic rash. The diagnosis was allergic contact dermatitis progressing to systemic allergic dermatitis [15].

Therefore, physicians should be aware of the possibility of anaphylaxis, allergy or hypersensitivity with corticosteroids. Drugs, including corticosteroids, should be given with caution in patients suffering from comorbid humoral atopic diathesis because such patients seem to have a higher risk of hypersensitivity. Complete and thorough previous history of drug reactions or allergy and clinical examination with prophylactic antiallergic measures including alternative corticosteroids, antihistamines, antiallergic monoclonal antibodies and ingectable epinephrine seem to be of paramount importance.

Acknowledgements

Not applicant.

Funding

None. 


\section{Availability of data and materials}

Not applicable.

\section{Authors' contributions}

NGK and IO analyzed and interpreted the previous collected data regarding anaphylactic shock, Kounis syndrome and hypersensitivity to corticosteroids. NGK, GDS and EC were the major contributor in writing and revising the manuscript. All authors read and approved the final manuscript.

Ethics approval and consent to participate

Not applicable.

\section{Consent for publication}

Not applicable.

\section{Competing interests}

The authors declare that they have no competing interests.

\section{Publisher's Note}

Springer Nature remains neutral with regard to jurisdictional claims in published maps and institutional affiliations.

\section{Author details}

'Department of Cardiology University of Patras Medical School, Rion, 7 Aratou Street, Queen Olgas Square, 26221 Patras, Achaia, Greece. ${ }^{2}$ Department of electrophysiology, Queen Elizabeth Hospital, Birmingham, England. ${ }^{3}$ Department of Cardiology Saint Andrews State General Hospital, Patras, Achaia, Greece. ${ }^{4}$ Krankenhaus der Barmherzigen Brüder, Trier, Germany.

Received: 12 September 2018 Accepted: 4 November 2018 Published online: 28 November 2018

\section{References}

1. Porcaro F, Paglietti MG, Diamanti A, Petreschi F, Schiavino A, Negro V, Pecora V, Fiocchi A, Cutrera R. Anaphylactic shock with methylprednisolone sodium succinate in a child with short bowel syndrome and cow's milk allergy. Ital J Pediatr. 2017;43(1):104.

2. La M, Tailor A, D'Amico M, Flower RJ, Perretti M. Analysis of the protection afforded by annexin 1 in ischemia-reperfusion injury: focus on neutrophil recruitment. Eur J Pharmacol. 2001;429:263-78.

3. Schmidt $M$, Lügering $N$, Lügering A, Pauels HG, Schulze-Osthoff $K$, Domschke W, Kucharzik T. Role of the CD95/CD95 ligand system in glucocorticoid-induced monocyte apoptosis. J Immunol. 2001;166:1344-51.

4. Vervoordeldonk MJ, Schalkwijk CG, Vishwanath BS, Aarsman AJ, van den Bosch H. Levels and localization of group II phospholipase A2 and annexin I in interleukin- and dexamethasone-treated rat mesangial cells: evidence against annexin mediation of the dexamethasone-induced inhibition of group II phospholipases A2. Biochim Biophys Acta. 1994;1224:541-50.

5. Burgdorff $T$, Venemalm L, Vogt $T$, Landthaler M, Stolz W. IgE-mediated anaphylactic reaction induced by succinate ester of methylprednisolone. Ann Allergy Asthma Immunol. 2002;89:425-8.

6. Ventura MT, Calogiuri GF, Matino MG, et al. Alternative glucocorticoids for use in cases of adverse reaction to systemic glucocorticoids: a study on 10 patients. Br J Dermatol. 2003;148:139-41.

7. Freedman MD, Schocket AL, Chapel N, et al. Anaphylaxis after intravenous methylprednisolone administration. JAMA. 1981;245:607-8.

8. Wilkinson M, Hollis S, Beck M. Reactions to other corticosteroids in patients with positive patch test reactions to budesonide. J Am Acad Dermatol. 1995;33:963-8

9. Kounis NG. Treatment of status asthmaticus. Br Med J. 1973;2(5867):663-4

10. Hsiao YP, Tsai JD, Muo CH, Tsai CH, Sung FC, Liao YT, et al. Atopic diseases and systemic lupus erythematosus: an epidemiological study of the risks and correlations. Int J Environ Res Public Health. 2014;11:8112-22.

11. Taniguchi T, Asano Y, Tamaki Z, Takahashi T, Ichimura Y, Toyama T, et al. Late-onset anaphylactic reactions following i.v. cyclophosphamide pulse in a patient with systemic sclerosis and systemic lupus erythematosus overlap syndrome. J Dermatol. 2014:41:912-4.

12. Son JH, Park SY, Cho YS, Chung BY, Kim HO, Park CW. Immediate hypersensitivity reactions induced by triamcinolone in a patient with atopic dermatitis. J Korean Med Sci. 2018;33:e87.
13. YIImaz M, Korkmaz H. Kounis syndrome: a paradoxal non-ST elevation myocardial infarction case after triamcinolone treatment for dermatitis. Turk Kardiyol Dern Ars. 2018:46:223-7.

14. Takahashi K, Asano T, Higashiyama Y, Koyano S. H, Takeuchi H, et al. two cases of anaphylactic shock by methylprednisolone in neuromyelitis optica. Mult Scler. 2018. https://doi.org/10.1177/1352458518763099 [Epub ahead of print].

15. Santos-Alarcón S, Benavente-Villegas FC, Farzanegan-Miñano R, PérezFrancés C, Sánchez-Motilla JM, Mateu-Puchades A. Delayed hypersensitivity to topical and systemic corticosteroids. Contact Dermatitis. 2018;78:86-8. 